\title{
PENSAR “A TUTTO TONDO”. EL TEMA DE LA VISIÓN TRIDIMENSIONAL EN NICOLÁS DE CUSA, JAN VAN EYCK Y LEONARDO DA VINCI
}

\author{
GIANLUCA CUOZZO \\ Dr. en Filosofía Teórica \\ gianluca.cuozzo@unito.it \\ Università degli Studi di Torino - Turín - Italia
}

Cómo citar este artículo:

G. Cuozzo. (2020). "Pensar 'a tutto tondo'. El tema de la visión tridimensional en Nicolás de Cusa, Jan van Eyck y Leonardo da Vinci” en Palabra y Razón. Revista de Teología, Filosofía y Ciencias de la Religión. No I8 Diciembre 2020, pp I4O-I64 https://doi.org/IO.29035/pyr.I8.I4O

\footnotetext{
I [N. del T.] La expresión "a tutto tondo", intraducible en castellano, alude al carácter integral de la escultura, que presenta todas las caras de las figuras que representa, hacia arriba y abajo y por todos lados, de manera circular, redonda ("tonda"). Dado que el autor utiliza esta expresión en el cuerpo del artículo como motivo de reflexión, a lo largo de la traducción he empleado diversas maneras, según el contexto, de traducir esta expresión, indicándola siempre en italiano, entre corchetes. Traducción al español de Hernán Guerrero-Troncoso, autorizada por el autor.
} 


\section{I) La plenitud escultórica de la intuición intelectual}

A pesar de la centralidad de la pintura en el Cusano (I4OI-I464), cuyo empleo metafórico toca muy a menudo el tema teológico de la explicatio creativa del mundo y del alma en tanto imágenes del absoluto ${ }^{2}$-por lo cual la relación entre principio y realidad contraida se replica en aquel entre el pintor y las figuras explicadas desde su ingenio ${ }^{3}-$, en su obra hay aspectos que van en la dirección de una revaloración, en términos filosóficos, del arte tridimensional por excelencia: la escultura. Ella, en el Cusano, más allá de algunos usos específicos en el ámbito de una rivaloración del saber técnico-artesanal, se vuelve metáfora del pensamiento en relieve (o visio circularis), en el cual se realiza -en tanto conocimiento de la realidad "a tutto tondo"- la visión (o intuitus) intelectual: facultad de asimilación de la realidad en su totalidad, más allá de toda perspectiva angular, con un giro de ojos capaz de ver el mundo en sus tres dimensiones. No es una casualidad que entonces el Cusano poseyera el De statua di L. B. Alberti (I458-I462), con el que tenía correspondencia a través de Giovanni Andrea de' Bussi (I4I7-I475), amigo y secretario personal del Cardinal: se trata del tercer opúsculo enviado de Alberti mismo a Bussi, «quod non magis ad pictorem quam ex multa parte ad architecti ingenium pertineat $»^{4}$, un tratado que espera que pueda ser leído en el futuro -come ya ocurrió con los anteriores- «cum voluptatem»: no está muy claro si, con esta expresión, Alberti se está dirigiendo a Bussi o, por intermedio de su persona, más bien al mismo Cusano.

Alberti, precisamente en esta obra, citado en la carta de Bussi junto al De pictura (I435) y a los Elementa picturae («pequeño tratado técnico-pedagógico» que antecede a aquel apenas mencionado5, siempre

\footnotetext{
2 N. de Cusa, De mente I5: h 2V, n. I48, lin. 8-II: «Unde mens est creata ab arte creatrice, quasi ars illa se ipsam creare vellet et, quia immultiplicabilis est infinita ars, quod tunc eius surgat imago, sicut si pictor se ipsum depingere vellet et, quia ipse non multiplicabilis, tunc se depingendo oriretur eius imago».

3 F. Frosini, Umanesimo e immagine dell'uomo. Note per un confronto tra Leonardo e Giovanni Pico, in Leonardo e Pico. Analogie, contatti, confronti, Atti del Convegno di Mirandola (IO maggio 2003), a cura di F. Frosini, Firenze, Olschki, 2005, pp. I82-I83; se vea también T. Leinkauf, Ut philosophia pictura - Beobachtungen zum Verhältnis von Denken und Fiktion, in Kann das Denken malen? Philosophie und Malerei in der Renaissance, a cura di I. Bocken e T. Borsche, Stuttgart, Fink, 2020, p. 52.

4 L. B. Alberti, cuando envió el De statua a Giovanni Andrea de' Bussi, amigo y secretario del Cusano, había remitido junto al texto la carta Ad Joannem Andream Bussum episcopum Aleriemsi. Esta misiva fue publicada por H. Mancini en L. B. Alberti, Opera inedita et pauca separatim impressa, Firenze, Sansoni, I890, p. 293.

5 E. di Stefano, L'altro sapere. Bello, arte, immagine in Leon Battista Alberti, Palermo, Centro Internazionale di Studi di Estetica, 2000, p. 8I.
} 
presente en la biblioteca del Cusano ${ }^{6}$ ), declaraba que era específico de esta forma de arte el hecho de extollere lo superfluo, para así hacer aparecer en la materia la forma buscada, «la cual antes estaba escondida ahí y en potencia». No es, entonces, para sorprenderse si una afirmación similar aparezca también en el Cusano, ahí donde él, discutiendo las doctrinas de los Peripatéticos, escribe «qui enim tollit in ligno partes, ut fiat ex ligno statua, addit de forma»; de esto se sigue «que las formas están en un cierto modo como posibilidad en la materia (hinc formae quodammodo possibiliter sunt in materia) y son realizadas en acto según las capacidades del eficiente» ${ }^{8}$. Ahora bien, con este procedimiento de sustracción de lo superfluo, que será central también en las empresas estatuarias de Michelangelo Buonarroti (I475-I564), le corresponde a los escultores -así escribe Alberti- hacer aparecer sus trabajos, «en la medida que puedan, a quien los observa muy naturales y similares a los cuerpos verdaderos hechos por la naturaleza» ${ }^{9}$. Me parece asimismo muy relevante que Marsilio Ficino -quien insertaba al Cusano en la larga trayectoria sapiencial de una philosophia perennis ${ }^{10}$ - atribuya este procedimiento de sustracción incluso a la creación divina: Dios, tal como hace el escultor con la materia, tiende a extraer la forma, la imagen de su rostro, de la naturaleza en la cual actúa: «quam ut eam [materiam] extollat ad sui

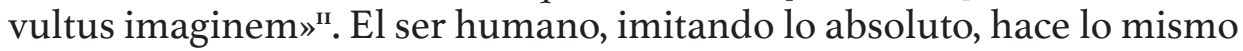
en el mundo del arte y de la técnica; es entonces necesario que, gracias a las artes humanas, de alguna parte en la materia, estimulada y alivianada del peso de eso que es inesencial, resplandezca en el modo más límpido la facies arteficis. En estas obras, de hecho, «el ánimo tiene un modo de expresarse y manifestarse hacia el exterior», del mismo modo como el «vultus hominis intuentis in speculum seipsum figurat in speculo»

6 Se trata del Códex Cusanus II2 (ff. 67r-73r ) de la Biblioteca del St. Nikolaus-Hospital (o Cusanusstift) de Bernkastel-Kues. Para una descripción de la biblioteca, véase P. Rotta, $\mathrm{La}$ biblioteca del Cusano, "Rivista di filosofia neoscolastica», XXI (1927), pp. 22-47; B. L. Ullman, Manuscripts of Nicholas of Cusa, «Speculum», VIII (1938), pp. I94-I97; así como también el trabajo más reciente de B. Bianca, Niccolò Cusano e la sua biblioteca: note, "notabilia", glosse, in Bibliothecae selectae da Cusano a Leopardi, a cura di Eugenio Canone, Firenze, Olschki, I993, pp. I-II.

7 N. de Cusa, De docta ign. II, 8: h III, p. 87, lin. 6-7.

8 Ibíd., lin. II-I2.

9 L. B. Alberti, Della statua, en Id., Della pittura e Della statua, ed. a cura di C. Bartoli, Milano, Società Tipografica dei Classici Italiani, I804, p. I09 (la cursiva es mía).

Io E. Garin, Storia della filosofia italiana, Torino, Einaudi, 1966, vol. I, p. 381. Aquí el autor se refiere a la célebre carta de Ficino a M. Uranio del II de junio I489, en la cual están indicadas las etapas progresivas de una única revelación filosófica (la pia philosophia, philosophica quaedam religio), que de Hermes y Platón pasa a través de Dionisio el Areopagita, Agustín, Boecio, Apuleyo, Calcidio, Macrobio, Avicebron, Alfarabi, Avicena, Enrique de Gante, Duns Escoto, Bessarión, llegando precisamente a retomar «quaedam speculationes Nicolai Cusani Cardinali».

II M. Ficino, Th. pl., (Théologie platonicienne de l'immortalité des âmes, texte critique établi et traduit par R. Marcel, 3 vols., Paris, Les Belles Lettres, 2007, vol. I, ) X, cap. 4., p. 584.

I2 Ibíd., II, 4, p. 108. 
Para la escultura, a causa de este rasgo de fidelidad mimética, vale en grado supremo la expresión aristotélica ars imitatur naturam (Fisica II c. 2, B I94a), citada por el Cusano en los Sermones XXXVIII' ${ }^{13}$ e CCXVI, como también en el De docta ignorantia ${ }^{14}$, tal como había sido reformulada por santo Tomás: «ars imitatur naturam in quantum potest» ${ }^{15}$. Esta sentencia, en particular, en la última homilía citada, está presente en el texto con esta ligera variación: «ars imitatur, quantum potest, naturam» ${ }^{16}$. El límite intrínseco de la realización artística, manifestado por la expresión "en la medida en que puede", hace que ella traslade en acto un quantum determinado por el infinito y absoluto poder-ser divino (posse esse, como síntesis perfecta del posse fierifactibilis y del posse facere facientis ${ }^{17}$ ); el hacer artístico, dadas las condiciones mundanas de la contracción, mucho más no puede hacer. Esa expresión aparece además, bajo la forma de un epígrafe, en muchos retratos realizados por Jan van Eyck: als ich kann: "como puedo, mucho más no puedo hacer, mejor que esto no podría pintar" -máxima rubricada en caracteres griegos mayúsculos en los cuales, como escribe Erwin Panofsky, en forma de anagrama del nombre del pintor, «un justo orgullo se mezcla de manera inimitable con una justa humildad $»^{18}$. En esta sentencia, en último término, se encuentra destilado todo el nuevo saber humanístico en relación con la posibilidad y los límites de los poderes del ser humano (posse cognoscere, posse facere) ${ }^{19}$; y de esta reflexión sobre la dignitas hominis emerge toda la distancia tomada por el Cusano entre creación ontológica divina (por la cual, en el absoluto, hay una perfecta coincidencia entre ser, pensar y crear) y la creación humana, que se limita solo a la producción de imágenes, conceptos y formas conjeturales (y a las respectivas derivaciones concretas bajo la forma de artificiata: obras de arte, instrumentos artesanales, juegos simbólicos, prácticas experimentales, etc. $)^{20}$ El

I3 N. de Cusa, Sermo XXXVIII (Sanctus, sanctus, sanctus, Coblenza I444): h XVIII, n. II, lin. 5.

I4 De docta ign. II, I: h I, p. 63, lin. 4-5.

I5 S. Tomás, Comm. in librum I Post. Anal., lectio I, n. 5.

I6 N. de Cusa, Sermo CCXVI A (Ubi est qui natus est Rex Iudaeorum?, Bressanone I456): h XIX, n. 27 , lin. 5 .

I7 Id., De ap. theor.: XII, n. 26, lin. 2.

I8 E. Panofsky, Early Netherlandish Painting, Cambridge, Mass, 1953, p. 326.

I9 Para la concepción del "límite" en la filosofía del Renacimiento, también en relación con el tema de la gracia, me remito a A. Dall'Igna, The presence of the theme of grace in the mysticism of Cusanus and Bruno, in Singularität und Universalität im Denken des Cusanus. Beiträge der 5. Jungcusanertagung II.-I3. Oktober 20I2, a cura di C. Ströbele, Regensburg, Roderer, 2015, pp. I23 I39. El autor está, además, desarrollando una interpretación original de esta categoría, afrontando una tradición especulativa que va de Giordano Bruno a Simone Weil.

20 N. de Cusa, De coni. I, I: h III, n. 5, lin. I-IO: «Coniecturas a mente nostra, uti realis mundus a divina infinita ratione, prodire oportet. Dum enim humana mens, alta dei similitudo, fecunditatem creatricis naturae, ut potest, participat, ex se ipsa, utimagine omnipotentis formae, in realium entium similitudine rationalia exserit. Coniecturalis itaque mundi humana mens forma exstitit 
espíritu, en cuanto creado, es sin duda finito y, aun así -como imago Dei, casi Deus incohatus y parvus mundus-, explora constantemente los propios límites, impulsándose más allá de los datos naturales, en un movimiento de progresión/perfeccionamiento que no tiene reposo. Esta concepción antropológica de tipo dinámico y simbólico ${ }^{21}$, in fieri, en la cual la idea del ser humano, más que ser algo ya predeterminado, se infiere de la búsqueda de la propia imagen originaria-casi como si el hombre, «sicut artifex vult statuam in lapide exsculpere», debiera esculpirse a sí mismo «in figura ideae et in eius imagine $»^{22}-$, no por casualidad, es restituida por el Cusano en referencia a términos y procedimientos artísticos:

Et quia imago numquam quantumcumque perfecta, si perfectior et conformior esse nequit exemplari, adeo perfecta est sicut quaecumque imperfecta imago, quae potentiam habet se semper plus et plus sine limitatione inaccessibili exemplari conformandi - in hoc enim infinitatem imaginis modo quo potest imitatur, quasi si pictor duas imagines faceret, quarum una mortua videretur actu sibi similior, alia autem minus similis viva, scilicet talis, quae se ipsam ex obiecto eius ad motum incitata conformiorem semper facere posset, nemo haesitat secundam perfectiorem quasi artem pictoris magis imitantem sic omnis mens, etiam et nostra, quamvis infra omnes sit creata, a Deo habet, ut modo quo potest sit artis infinitae perfecta et viva imago ${ }^{23}$.

En este sentido, la esencia humana, sobre la base del carácter dinámico ofrecido por el motivo del hombre ad Dei immortalem imaginem $^{24}$, en cuando consciente de esta misma semejanza fundante, se manifestaría en el hecho de ser «un intérprete y creador de símbolos» útiles a su misma definición en relación con el absoluto: la antropología del Renacimiento, escribe João Maria André, hace del hombre sobre todo un "productor de cultura», capaz de crear por sí mismo, autónomamente, aquel patrimonio variopinto de valores culturales,

uti realis divina. Quapropter ut absoluta illa divina entitas est omne id quod est in quolibet quod est, ita et mentis humanae unitas est coniecturarum suarum entitas. Deus autem omnia propter se ipsum operatur, ut intellectuale sit principium pariter et finis omnium; ita quidem rationalis mundi explicatio, a nostra complicante mente progrediens, propter ipsam est fabricatricem».

2I J. M. André, Arte e natura: il ripensamento del tema della imitatio in Nicola Cusano, en «Filosofia», LXIV (2019), p. II9.

22 N. de Cusa, De docta ign. II, IO: h I, p. 97, lin. 8-9. Sobre esta situación de coimplicación recíproca entre idea (que guía la realización de la obra) y ejecución artística (de la cual solo se puede derivar la forma), el Cusano escribe «oritur autem ex exercitio artis ars - «fabrificando fabri fiemus» -, et ita ars oritur de exercitio artificis» (Sermo XXXVIII, h. XVIII, n. Io, lin. I3-I5).

23 Id., De mente, I5: h 2V, n. I48, lin. I-22. Un pasaje análogo se encuentra en la Epistula ad Nicolaum Bononiensem (II giugno I463), n. 7-8, lin. I4-23.

24 M. Ficino, De raptu Pauli, en Id., Théologie platonicienne de l'immortalité des âmes, texte critique établi et traduit par R. Marcel, 3 vols., Paris, Les Belles Lettres, 2007, vol. I, Opuscola theologica, XXVIII, p. 965. 
imágenes y exempla que son su segunda naturaleza, desplegando con eso las últimas potencialidades de la realidad creatural y recurriendo de nuevo -en una operación de una verdadera y genuina explicatio concreativa que tiene como protagonista al intelecto- al infinito poder del principio ${ }^{25}$. El ser humano, gracias a estas creaciones suyas, como en efecto afirmaba Ficino, «est quidam Deus», mostrándose así libre de la naturaleza y de necesidades exteriores como el destino o la fortuna ${ }^{26}$; de modo tal que, explica luego Ficino, «la mente reivindica para sí un derecho divino no solamente [...] cuando da forma y plasma la materia (formanda et figuranda per rationem artis materia), sino también cuando -imitando a Dios $[N d A]$ - con su poder modifica la naturaleza de las $\operatorname{cosas}^{27}$, introduciendo en la naturaleza misma el reino del arte y de los artefacto humanos, es decir, todo aquello que encontramos delante de nosotros y de lo cual somos indiscutiblemente autores. Se trata de objetos e instrumentos dispuestos a ser utilizados para el perfeccionamiento histórico de aquel mundus hominum (hecho de virtudes, obras de arte, instituciones, instrumentos técnicos, etc.), el cual, como sabemos, ha hecho grande al hombre del Renacimiento, llegando hasta nosotros en forma de exemplum inalcanzable. Desde aquí en adelante, escribe Hans Blumenberg con un énfasis un poco exagerado, «el hombre ya no mira hacia la naturaleza, hacia el cosmos, para deducir su lugar propio entre los seres, sino al mundo de las cosas de las cuales se ha generado la sola humana arte» $^{28}$.

Obviamente, en lo que respecta a los referentes del arte escultórica, no se puede olvidar el ejemplo del sabio grabador de cucharas de madera reflectantes, nudo metafórico fundamental del Idiota de mente (I450), aún cuando la metáfora estaba presente embrionariamente en el De docta ignorantia ${ }^{29}$. Las siguientes expresiones, puestas en boca del idiotaartesano, son funcionales para el andamiaje simbólico de la creación del alma de parte de Dios según correctas proporciones matemáticas; sin diferir de lo que se ha señalado, mediante el caso del alfarero que sopla el vidrio (y del spiritus vitrificator insuflado en el vidrio por el mismo

25 Cfr. J. M. André, O Homem como Microcosmo. Da concepção dinâmica do homem em Nicolau de Cusa à inflexão espiritualista da anthropologia de Ficino, en "Philosophica", I4 (1999), p. 23.

26 M. Ficino, Th. Pl., XIII, 3, p. 1229.

27 Ibíd., XIII, 4, p. I239.

28 H. Blumenberg, Le realtà in cui viviamo (198I), trad. it. di M. Cometa, Mialno, Feltrinelli, I987, p. 54. Tomo distancia de lo que el autor escribe, pp. 56-57, acerca del supuesto escaso relieve del tema de la imitatio para el nacimiento del pensamiento técnico moderno. La interpretación de la figura del "idiota" del Cusano resulta particularmente equívoca.

29 N. de Cusa, De docta ign. II, 8; h I, p. 86, lin. 22-25: «Unde aiebant veteres Stoici formas omnes in possibilitate actu esse, sed latitare et per sublationem tegumenti apparere, quemadmodum si coclear ex ligno fit per ablationem partium tantum». 
artesano), en el Dialogus de genesi (I447) ${ }^{30}$ : también en este caso emerge la doctrina cusana del valor ontológico de la belleza o armonía como resultado de una operación de esencialización -una casi rarefacciónespiritualización- de la materia a través de la disposición racional y proporcional de sus partes (en la cual, por lo tanto, parece un momento determinante la sustracción de lo superfluo).

Volui facere coclear speculare. Quaesivi lignum valde unitum et nobile super omnia. Applicui instrumenta, quorum motu elicui convenientem proportionem, in qua forma coclearis perfecte resplenderet. Post haec perpolivi coclearis superficiem adeo, quod induxi in resplendentiam formae coclearis formam specularem, ut vides. Nam cum sit perpulchrum coclear, est tamen cum hoc coclear speculare [...] Unde forma specularis non habuit temporale esse ante coclear, sed ad perfectionem coclearis addita est per me formae primae coclearis, ut eam perficeret, ut nunc forma specularis in se contineat formam coclearis. Et forma specularis est independens a cocleari. Non est enim de essentia speculi, quod sit coclear. Quare si rumperentur proportiones, sine quibus forma coclearis esse nequit, puta si manubrium separaretur, desineret esse coclear, sed ob hoc forma specularis non desineret esse. Ita quidem deus per motum caeli de apta materia proportionem eduxit, in qua resplenderet animalitas perfectiori modo, cui deinde addidit mentem quasi vivum speculum modo quo dixi ${ }^{31}$.

Para estos y otros ejemplos similares extraídos del mundo artesanal (saber técnico-aplicado nacido de la experiencia, «alimento natural» de la verdadera ciencia ${ }^{32}$ ), valga la formula acuñada por Luca Pacioli (I445I5I7), verdadero y genuino punto de encuentro filosófico entre el Cusano y Leonardo da Vinci (I452-I519): «el sastre y el zapatero usan la geometría y no saben que cosa es. Los albañiles y carpinteros, herreros y todos los artífices usan la medida y la proporción y no lo saben. Pero tal como otras veces se ha dicho, todo consiste en el número, el peso y la medida»33.

30 Id., De gen. 3: h IV, n. I63, lin. 6-22.

3I Id., De mente 5: h 2V, n. 86, lin. 4-I5.

32 Id., De sap. I; h 2V, n. 3, lin. 5-6.

33 L. Pacioli, De divina proportione III, cap. LIV. Se trata de un manuscrito concluido por Pacioli en I498, del cual existe una copia en la Biblioteca Ambrosiana de Milán (cfr. la reproducción anastática editada por A. Marinoni, Fontes Ambrosiani in lucem editi cura et studio Bibliothecae Ambrosianae LXXII, Milano, Silvana Editoriale, 20IO). La edición impresa, de la cual cito, aparece en Venecia en $\mathbf{5} 509$ por el editor Alessandro Paganino de' Paganini. El volumen comprende, además de la Divina porportione, el Tractato del'architectura (del mismo Pacioli), así como también un Libellus in tres partiales tractatus divisus quinque corporum regolarium et dependentium, que no es sino la versión en vulgar del Libellus de quinque corporibus regularibus de Piero della Francesca, y concluye con la demostración de la construcción de las letras mayúsculas del alfabeto mediante regla y compás. Cfr. A. Marinoni, Introduzione a L. Pacioli, De divina proportione, cit., p. 4. 


\section{2) Ante el espejo de la imagen: Cusano, Jan van Eyck y Giorgione}

A través de la metáfora escultórica, en el Cusano se ingresa a un tema central incluso desde el punto de vista epistemológico. Esto se deduce apenas uno se da cuenta del significado traslaticio de la expresión dar relieve (en lat.: insigniorem rem facere), con el cual el escultor identifica y lleva a cabo los rasgos de la obra, teniendo ante la vista la semejanza de la naturaleza, con el auxilio de dos instrumentos: la medida y el poner los términos ${ }^{34}$. La expresión "dar relevancia", en efecto, es también válida en el plano de un concepto, de una doctrina, por ejemplo, en el sentido de "poner en evidencia", "acentuar un significado", "hacer resaltar del fondo una idea o noción", como cuando se dice, con intención demostrativa, "ante oculos pono, in lucem profēro". Esta situación nos vuelve a llevar al tema de la visión circular (simultanea et incontracta visio $)^{35}$, metáfora del intellectualis intuitus, capaz de resumir en una mirada instantánea toda la topografía -arriba y abajo, de oriente a occidentede la cosa intencionada por la mirada, la cual aparece así reconstituida mágicamente, casi por todos lados (a tutto tondo), en la recomposición de aquellas que en lenguaje fenomenológico se llamarían las varias Abschattungen de una cierta cosa intencionada por la vista ${ }^{36}$. Como si esta realidad fuera vista a la vez frontalmente (según el rayo céntrico, definido por Alberti «el capitán, el príncipe de los radios») y, a la vez, mediante un espejo puestro detrás de ella, espejo capaz de revelar aspectos no accesibles directamente, según la perspectiva frontal, de la cosa puesta ante la mirada.

Como ejemplo artístico de esta visión al mismo tiempo directa y refleja, podemos pensar en la obra pictórica del ya mencionado Jan van Eyck, El matrimonio Arnolfini (I434), en el cual un espejo pintado en la pared a espaldas de los personajes retratados permite verlos de espaldas, junto al pintor mismo que pretende observar la escena (aún cuando este último resulte colocado, como cualquier otro asistente, desapercibido, fuera del campo de la perspectiva del observador). Pero el espejo está rodeado -pintura en la pintura- por diez minúsculos tondos, en los cuales están representados los episodos más relevantes de la Pasión de Cristo: el espejo, entonces, representa también el ojo divino, superior

34 L. B. Alberti, Della statua, cit., p. II2.

35 N. de Cusa, De vis. 2: h VI, n. 2, lin. 7-9: «Visus autem absolutus ab omni contractione simul et semel omnes et singulos videndi modos complectitur quasi adaequatissima visuum omnium mensura et exemplar verissimum».

36 Cfr. E. Husserl, Ideen zu einer reinen Phänomenologie und Phänomenologischen Philosophie (I9I2I929), a cura di K. Schuhmann, vol. I (Allgemeine Einführung in die reine Phänomenologie), 3, Berlino, Springer, 1976, pp. 493-498. 
a toda perspectiva angular, siempre sujeta a una cierta amplitud y profundidad de la mirada (por lo cual, escribe el Cusano, nuestro ojo siempre «per angulum quantum videt» ${ }^{37}$ ). En este sentido, el espejo de Jan van Eyck, «enmarcado en una corona de círculos con los episodios de la vida y la muerte de Cristo que se desarrollan como en un planisferio, constituye un microcosmos ${ }^{38}$ de la visión, una especie de panóptico ante litteram $^{39}$, aunque de orden metafísico-teológico; en él, al contrario de lo que ocurre en el edificio carcelario de Bentham, todavía es posible una simetría o reciprocidad de las miradas. Como sea, una simetría parcial, que tiene su propio límite en el visus absolutus de Dios; así como cada vez que veo la imagen del omnividente, me debo entonces recordar que es Dios quien en primer lugar me mira a mí, «antes incluso que yo me dirija a Él»: «Videndo me das te a me videri» ${ }^{40}$.

37 N. de Cusa, De vis., 8: h VI, n. 30, lin. 15.

38 J. Baltrušaitis, Lo specchio: rivelazioni, inganni e science-fiction (1978), trad. it. de C. Pizzorusso, Milano, Adelphi, 2007, p. 252.

39 La concepción arquitectónico-política del Panopticon de Bentham, escribe Michel Foucault, es una cosa evidente (Sorvegliare e punire. Nascita della prigione (I975), trad. it. de A. Tarchetti, Torino, Einaudi, 20I4, p. 2I8): «a la periferia una construcción como anillo; al centro, una torre cortada por anchas ventanas que se abren hacia la fachada interna del anillo; la construcción periférica está dividida en celdas, que ocupan cada uno todo el grueso de la construcción; ellas tienen dos ventanas, una hacia el interior, correspondiente a la ventana de la torre; la otra, hacia el exterior, permite a la luz atravesar la celda de una parte a otra. Basta entonces poner un vigilante en la torre central, y en cada celda encerrar a un loco, a un enfermo, a un condenado, a un obrero o a un erudito. Por efecto del contraluz, se pueden captar desde la torre, destacándose exactamente, las pequeñas silhouettes prisioneras en las celdas de la periferia. Tantas jaulas en la cuales cada actor está solo, perfectamente individualizado y constantemente visible».

40 N. de Cusa, De vis. 5: h V, n. I3, lin. I2. 


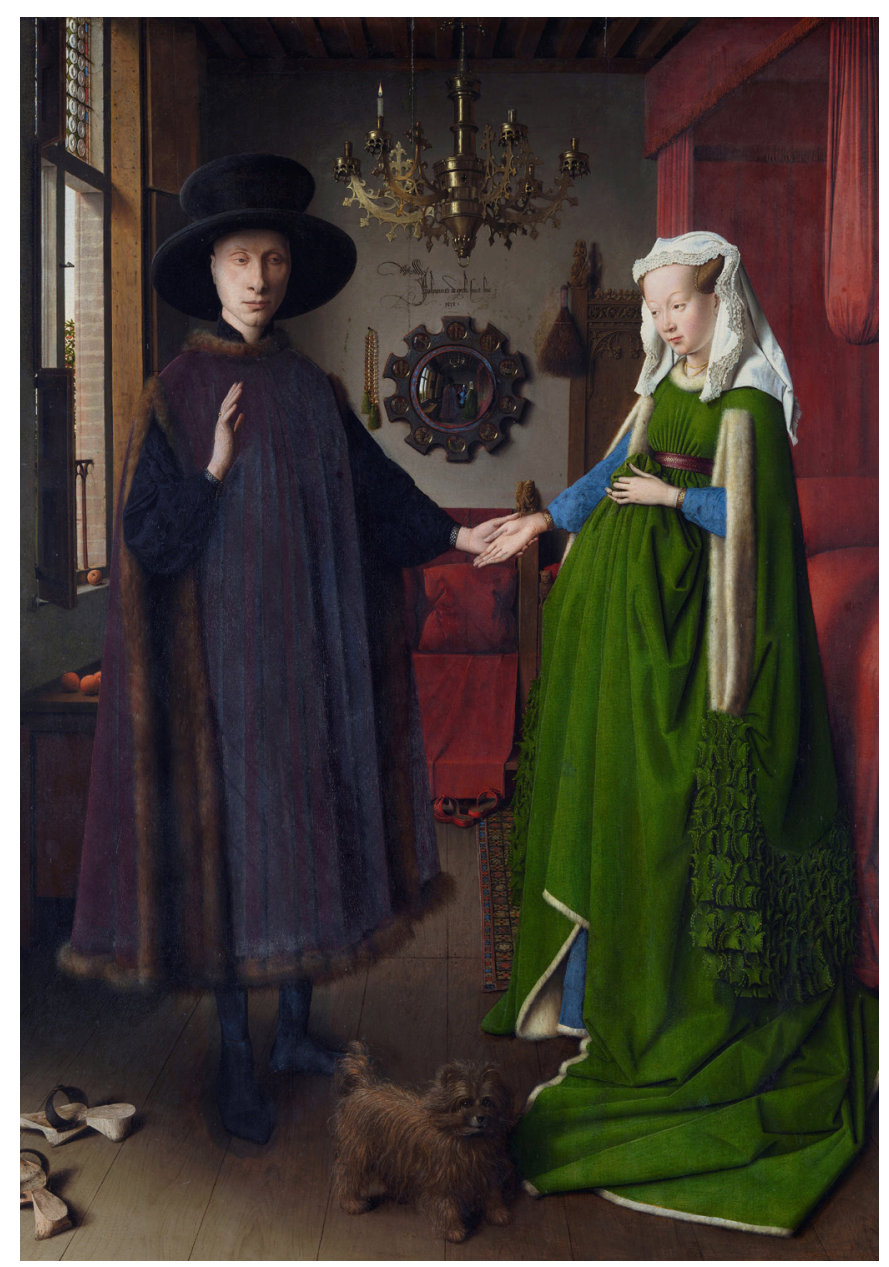

Jan van Eyck, El matrimonio Arnolfini (I434), óleo sobre madera, National Gallery (Londres).

En el Cusano, como en Rogier van der Weyden ${ }^{41}$ y en el mismo Jan van Eyck (en el cual «el espejo es un lugar puesto al interior del cuadro, a menudo decorado como un ostensorio o un reliquiario, que circunscribe la manifestación de un mundo distinto: a su interior consiente de ver un más allá»), el espejo es entonces un objeto revelador «que permite

4I Se trata del mismo Rogerius (Tournai ca. I40o - Bruselas I464) del cual habla el Cusano en el Prefatio al De visione Dei, autor de una imagen cuncta videns, tal que quasi omnia circumspiciat; detalle de una pintura que al tiempo del Cusano, como él mismo atestigua, estaba colgado en el tribunal de Bruselas. Se trata de una pintura hoy perdida, pero cuya copia fue reproducida al lado derecho de un tapiz conservado en el Museo de Berna que representa uno de los Ejemplos de Justicia (Justicia de Trajano). 
ver eso que lo anima desde ya más allá o más acá de las apariencias» ${ }^{42}$ : la realidad verdadera e incontracta del absoluto, que no obstante no aparece directamente en la escena pictórica. En el De filiatione Dei (I445) esta dilatación de la mirada natural resulta evidente en el momento en que el Cusano observa que cada espejo contraído (la pluralidad de las mentes), que se transfunde en el speculum central e infinito del Verbum (el speculum veritatis, absolutamente plano y perfecto) ${ }^{43}$, ve reflejarse en él tanto a sí mismo como cualquier otro espejo creatural (el que, como tal era inaccesible a su mirada perspectiva).

Quando igitur aliquod intellectuale vivum speculum translatum fuerit ad speculum primum veritatis rectum, in quo veraciter omnia uti sunt absque defectu resplendent, tunc speculum ipsum veritatis cum omni receptione omnium speculorum se transfundit in intellectuale vivum speculum, et ipsum tale intellectuale in se recipit specularem illum radium speculi veritatis in se habentis omnium speculorum veritatem ${ }^{44}$.

Volviendo al Matrimonio Arnolfini, para explicar esta convergencia de las miradas favorecido por el punto de fuga encarnado en el espejo colocado a espaldas de los personajes retratados -en el cual el observador se refleja/transfunde tanto en la mirada del pintor, como en el absolutus vultus de Dios, «ejemplar y verdad de todos los rostros» ${ }^{45}$ se puede aludir a la figura $\mathrm{P}$ al centro del De coniecturis (I445): figura eurística útil para estudiar «todos los modos de la visión y de cada uno» ${ }^{46}$, constituida por la intersección entre dos pirámides visivas que se reflejan la una en la otra, engendrando -como en un juego de espejosuna visión meta-perspectiva, la cual abre el espacio de la aprehensión humana más allá de toda visión angular. La pirámide visiva albertina ${ }^{47}$, por una especie de rebote óptico, en el doble retrato de Jan van Eyck se desdobla en dos perspectivas contrarias y complementarias: una externa, que tiene por objeto el cuadro (aquella del pintor, el cual, como nosotros

42 M. de Certeau, Nicolas de Cues, le secret d’un regard, en «Traverses» (marzo I984), n. 30-3I, p. 7I.

43 Sobre la temática del Verbum en el Cusano, véase la contribución fundamental de $\mathrm{H}$. Schwaetzer, Aequalitas. Erkenntnistheoretische und soziale Implikationen eines christologischen Begriffs bei Nikolaus von Kues. Eine Studie zu seiner Schrift De aequalitate, Hildesheim, Olms, 2004; véase también Verbum et imago coincidunt. Il linguaggio come specchio vivo in Cusano, a cura di G. Cuozzo, A. Dall'Igna, J. González Ríos, D. Molgaray e G. Venturelli, Milano-Udine, Mimesis, 2019. 44 N. de Cusa, De fil. 3: h. IV, n. 67, lin. I-7.

45 Id., De vis. 6: h VI, n. II9, lin. $2 \mathrm{I}$.

46 Id., De coni. II, I: h III, n. 73, lin. 5 .

47 Para un análisis en profundidad de las aplicaciones concretas, desde el punto de vista de la medición, de la pirámide visual de Leon Battista Alberti, cfr. T. Müller, Perspektivität und Unendlichkeit. Mathematik und ihre Anwendung in der Frührenaissance am Beispiel von Alberti und Cusanus, Regensburg, Roderer, 2010, pp. 168-170. 
los observadores, ve la tabla frontalmente, más acá de la habitación representada), y una interna, entretejida visivamente al interior del retrato, que nos tiene a nosotros que miramos (aquellos que deberían ser quienes disfrutan la escena representada en la pintura) como objeto de una visión diversa, contraria y superior a la nuestra. Se trata de la mirada divina, cuyo oculus-speculum, vértice de una pirámide opuesta a aquella generada por nuestro ojo, está puesto más allá de toda visión perspectiva y angular: mirada omnicomprensiva y sine perspectiva capaz de comprender en sí toda la perspectiva externa («el espacio terrestre», articulada por la multiplicidad de las pirámides visivas contractas que son las mentes), sea aquella intrínseca a la pintura («el espacio celeste ${ }^{48}$ ), dando lugar a una maravillosa coincidencia de videre y videri - «videndo me das te a me videri, qui es Deus absconditus» ${ }^{49}$.
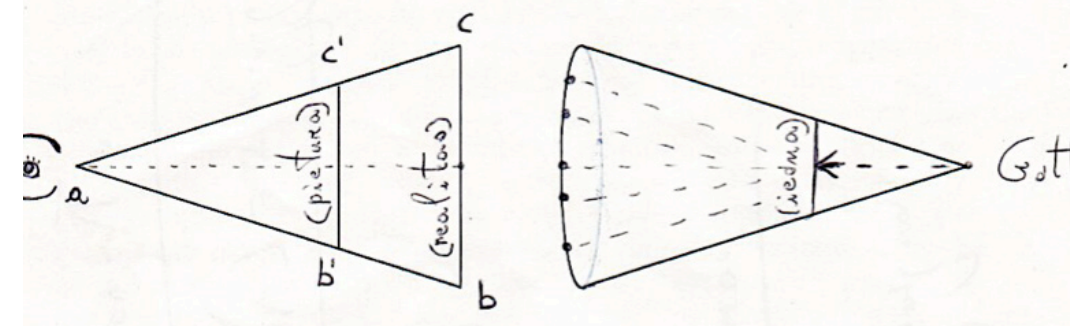

Descomposición de la figura $\mathrm{P}$ en la perspectiva humana (o terrestre), a la izquierda, y en la divina (o celeste), a la derecha

(dibujo a mano obra del autor)

Que Alberti no es ajeno a esta doctrina de la visión pluriperspectiva sia esente da questa dottrina della visione pluri-prospettica está atestiguado por el emblema de bronce realizado, para el artista mismo, por el escultor Matteo de' Pasti entre el I446 y el I450, medalla que representa un ojo rodeado de alas de aguila, bajo el cual se puede leer la sentencia de sabor ciceroniano quid tum (¿y entonces? ¿y bien?): el ojo alado, podría parecer, está al origen de una perspectiva omnividente y simultánea (absoluta visio), cuya pirámide visiva -por amplitud y

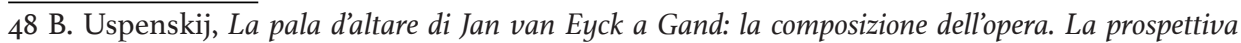
divina e la prospettiva umana (1994), trad. it. de R. Salvatore, Milano, Lupetti, 200I, cit., p. 30.

49 N. de Cusa, De vis. 5: h VI, n. I3, lin. I2. 
rapidez- resulta absolutamente incomparable respecto a las diversas perspectivas cuantitativas, siempre sujetas a una determinada grandeza, que caracterizan la experiencia humana de la visión. Respecto a la «ubiquidad del Dios omnisciente ${ }^{50}$-en cuya mirada confluyen agudeza, amplitud y velocidad-, la visión contracta humana es demasiado similar a aquella de Monopo, personaje de la segunda de las Intercenales albertinas: se trata del más viejo y sabio de los sacerdotes, el cual, como dice el nombre, ha solo un ojo. Este, por su perspectiva restringida y lagunosa, cree incluso que el verdadero Dios se pueda identificar con el dinero; y esto a causa de un banal malentendido: sobre el altar del dios Apolo, de hecho, encuentra casualmente una moneda olvidada por alguien, confundiéndola con la respuesta del verdadero dios ${ }^{51}$. La antítesis a la restricción angular de Monopo -el verdadero habitante de una Tierra plana y sin profundidad, muy similar a los personajes de Flatland (I882) descritos por E. A. Abbott ${ }^{52}$ es la visio circularis, que está en primer lugar, como el círculo antes que el polígono inscrito en aquel por los lados y los ángulos:

Intellectus igitur, qui non est veritas, numquam veritatem adeo praecise comprehendit, quin per infinitum praecisius comprehendi possit, habens se ad veritatem sicut polygonia ad circulum, quae quanto inscripta plurium angulorum fuerit, tanto similior circulo, numquam tamen efficitur aequalis, etiam si angulos in infinitum multiplicaverit, nisi in identitatem cum circulo se resolvat ${ }^{53}$.

El Cusano, en un pasaje muy interesante, de muestra sensible a este tema de la "visión escultórica", pasaje que resume de manera taxativa todo el ludus iconae: aquella experimentalis praxis, a saber, la que tiene por objeto la pintura del Cristo cuncta videns, obra pictórica realizada al modo de «Rogerius maximus pictor» ${ }^{54}$, alias Rogier van der Weyden, contemporáneo de Jan van Eyck. En efecto, así escribe el Cusano en el De visione Dei (I453), quien intuye intelectualmente lo verdadero

50 E. Wind, Misteri pagani nel Rinascimento (1968), trad. it. de P. Bertolucci, Milano, Adelphi, 1999, p. 284. Cfr. también F. P. Fiore, Gli inizi, in Aa.Vv., Leon Battista Alberti e l'architettura, a cura di M. Bulgarelli, A. Calzona, M. Ceriana y F.P. Fiore, Milano, Silvana Editoriale, 2006, pp. 2I2-32I.

5I L. B. Alberti, Intercenales (I439), a cura di I. Garchella, Napoli, ESI, I998, II 6, pp. 6o-6I.

52 E. A. Abbott, Flatlandia. Racconto fantastico a più dimensioni (I884), trad. it. M. D'Amico, Milano, Adelphi, 1993, p. 32: «Imagínense una vasta hoja de papel sobre la cual líneas rectas, triángulos, cuadrados, pentágonos, hexágonos y otras figuras geométricas, en vez de permanecer inmóviles en su lugar, se mueven por aquí y por allá, libremente, sobre la superficie o dentro de ella, pero sin poder levantarse de ahí ni poder sumergirse ahí, en fin, como si fueran sombras, pero concretas y con contornos luminosos».

53 N. de Cusa, De docta ign. I, 3: h I, p. 9, lin. I4-20.

54 Id., De vis. I: h VI, n. 2, lin. 8. 
absoluto debería adecuar -al menos por aproximación- la mens divina omnipotens $^{55}$, para la cual «visus est oculus sphaericitatis et perfectionis infinitae»; este, por lo tanto, "ve las cosas, al mismo tiempo, alrededor, hacia arriba y hacia abajo (in circuito et sursum e deorsum simul videt) ${ }^{56}$, como si se tratara de admirar una escultura girando alrededor de ella, registranfo paso a paso los relieves, lo que hay de convexo y cóncavo en la superficie tridimensional. La verdad, también en el Cusano, posee aquella plenitud de la cual es inspiradora la «más gorda Minerva» de la cual habla Alberti ${ }^{57}$, contra las certezas de los teóricos abstractos (Alberti piensa, en particular, en los matemáticos de profesión, lejanos a toda forma de aplicación concreta de su propio saber $)^{58}$ : una plenitud y concreción de la cual sobre todo son capaces los artistas, en grado de transformar la visión en un saber abrazar con la mirada la verdad como si ella fuera un cuerpo en relieve, en todo semejante a aquellos hechos por la naturaleza. He propuesto, entonces, para el Cusano, la fórmula de una "visión escultórica", tridimensional, del todo, en conformidad al tema de una sapida scientia que tiene por objeto a Cristo, «qui est vita, est et sapientia»: «scientia in eo, quia sapida, ostenditur viva apprehensio»"

Esta propensión a la concreción de la intuición está en línea con los tentativos pictóricos llevados a cabo por Leonardo da Vinci, cuya visión perspectiva puede ser definida como un «mirar la realidad por dentro ${ }^{60}$, haciendo con artificio eso que para el escultor está completamente dado por descontado, a saber, dar un sentido de tridimensionalidad a las imágenes representadas sobre la superficie bidimensional de la pintura, de modo tal que las figuras retratadas estén vivas y no «muertas dos veces» ${ }^{6}$. Leonardo, para alcanzar este efecto ilusionista, además del sabio uso del claroscuro (fundado, por lo demás, en una adaptación original de la figura $\mathrm{P}^{62}$ ), recurrió al método de la variación e integración de la perspectiva. Este estratagema es definido por el pintor y teórico del arte Giovanni Paolo Lomazzo (I538-I592) «arte de las flexiones», con una clara

55 Id., De ludo I: h IX, n. 46, lin. I4.

56 Id., De vis. 8: h VI, n. 30, lin. I7-I8.

57 L. B. Alberti, Ludi mathematici, a cura di R. Rinaldi, Carta dedicatoria a Meliaduso D'Este, Milano, Guanda, 1980, p. 4I.

58 Sobre estos aspectos se vea el buen ensayo de T. Leinkauf, Ut philosophia pictura Beobachtungen zum Verhältnis von Denken und Fiktion, cit., pp. 48-49.

59 N. de Cusa, De ludo II: h IX, n. 70, lin. 9.

6o F. M. Bongioanni, Leonardo pensatore. Saggio sulla posizione filosofica di Leonardo da Vinci, Piacenza, Soc. Tipografica Ed. Porta, 1935, p. I0.

6I Leonardo, Trattato della pittura, in Id., Scritti. Tutte le opere: Trattato della pittura, Scritti letterari, Scritti scientifici, a cura di J. Recupero, Milano, Rusconi, 2002, cap. 366, p. 155.

62 Para estos aspectos remito a mi Dentro limmagine. Natura, arte e prospettiva in Leonardo da vinci, Bologna, il Mulino, 2013, pp. 86-IO4. 
referencia a Leonardo da Vinci, un arte del cual también fue maestro Alberto Durero (Albrecht Dürer) en la tercera parte de su Simetría de los cuerpos humanos ${ }^{63}$. Se trata de las «tranportaciones en todos sus destellos» del modelo a representar, ángulos visuales «que resultan admirables por su gallardo y seguro giro de los miembros, che riescono mirabili per il loro gagliardo e sicuro girare di membra, de modo tal que se ven casi, por decirlo así, también por las otras partes» ${ }^{64}$. Giorgio Vasari, por su parte, exaltando este procedimiento de escansión sucesiva de los diversos planteamientos de un objeto a representar, casi girando alrededor de él, recuerda cómo Giorgione da Castelfranco -en la búsqueda en pintura del relieve- había sido estimulado por los estudios de Leonardo, en particular aquellos relativos a la reproducción simultánea de la misma figura según ángulos visuales diversos ${ }^{65}$. Giorgione, con una feliz intuición, hizo un experimento pictórico análogo poniendo el modelo a retratar en un «círuclo de espejos» ideal ${ }^{66}$, ejemplos en los cuales hay una fuerte asonancia con la praxis sugerida en el De filiatione Dei, donde las mentes creadas, equiparadas a espejos más o menos contractos, están dispuestos en círculo en torno al espejo infinito de la verdad ${ }^{67}$. Giorgione, así recuerda Vasari, se habría dedicado a una figura masculina «de la cual había visto lo de adelante y lo de atrás y los dos perfiles de los lados», pintando un «desnudo que daba la espalda y tenía en el suelo una fuente de agua limpidísima, en la cual hizo adentro por reverberación la parte de adelante; y en uno de los lados había un pequeño peto bronceado que se había despojado, en el cual estaba el perfil zurdo, porque en el resplando de esas armas se divisaban todas las cosas; por la otra parte había un espejo, dentro del cual estaba el otro lado de ese desnudo» ${ }^{68}$. La figura desnuda, tomada de espaldas, a través de este artificio pluriperspectivo, resultaba de este modo circundada por tres espejos reveladores (y por lo tanto tres pirámides visuales): la poza de agua a

63 Se trata de la traducción italiana de los Vier Bücher der menschlichen Proportion (I528) realizada por Paolo Gallucci (I538-I63I), matemático, astrónomo y cosmógrafo insigne, deudor de las doctrinas de Regiomontano (Johannes Müller), traducción que apareció en Venecia en I59I.

64 G. P. Lomazzo, Trattato dell'arte della pittura, scultura et architettura (Milano, Paolo Gottardo Pontio, 1584), citado según la edición de I844, Roma, Tipografia di Giuseppe Gismondi (Reproducción anastática Elibron Classics, Marston Gate, 2006), Libro V, cap. II, p. 22I.

65 Como ejemplo se puede pensar aquí al dibujo 15573 de la Biblioteca Real de Turín, el Triple retrato viril (¿César Borgia?).

66 S. Bramly, Leonardo da Vinci. Artista, scienziato, filosofo, trad. it. de M. Salemi Cardini, Milano, Mondadori, 20II, p. 27.

67 N. de Cusa, De dato 2: h IV, n. 99, lin. I4-I7: «Solum est speculum unum sine macula, scilicet deus ipse, in quo recipitur uti est, quia non est illud speculum aliud ab aliquo quod est, sed est id ipsum quod est in omni eo quod est, quia est universalis forma essendi».

68 G. Vasari, Le vite de' più eccellenti pittori, scultori e architettori, en las redacciones de 1550 y 1568 , a cura di R. Bettarini e P. Barocchi, Firenze, Sansoni, 1976, Proemio, p. 46; cfr. P.C. Marani, Leonardo. Una carriera di pittore, Milano, Federico Motta, 2003, p. I96b. 
espaldas del personaje, un espejo de bronce (propuesto por los calzados brillantes de la armadura) y un espejo verdadero y genuino, casi como si Giorgione estuviera proponiendo una fenomenología progresiva del aparecer reflejo, a través de los varios grados de perfección ofrecidos por las superficies especulares: el agua (elemento inestable y distorsionador de las apariencias, del cual fue víctima Narciso cuando se enamoró de su propia imagen, si bien «non aliud a se ipso vidit»" ${ }^{69}$ ), la superficie de bronce (elemento estable pero todavía afectado por la opacidad), y el espejo (culmen de la autoconsciencia fenoménica que se obtiene por medio del artefacto humano que es más fiel en la restitución de la apariencia refleja de una cosa dada). Esta obra, lamentablemente, como muchas otras realizadas por Giorgione, se extravió.

Es interesante que, del lado teológico-filosófico, la misma función (de integración perspectiva) garantizada por el espejo, en el Cusano, en el De visione Dei, se ejercida por la fe, una suerte de speculum fidei, capaz de coadyuvar a los instrumentos lógico-formales a los cuales se confía la razón, revelnado a la mente un lado de la realidad de otra manera inaccesible, con el solo principio de identidad y no-contradicción (principios racionales a la base de la perspectiva geométrico-lineal). Esto se evidencia en el episodio, lleno de suspense, de la superación de aquel estado de interdicción en el cual se encuentran los monjes de Tegernsee frente a una imagen que, contra toda expectativa, resulta ser capaz de seguir como una sombra, a cada uno individualmente y a todos juntos (simul et semel), sus movimientos divergentes y contradictorios: esto va, para la lógica binaria del discurso (fundada en un aut-aut que excluye cualquier opción que exceda la identidad de él mismo), fuera de todo sentido plausible.

Et dum hoc experiri volens fecerit confratrem intuendo eiconam transire de oriente ad occasum, quando ipse de occasu pergit ad orientem, et interrogaverit obviantem, si continue secum visus eiconae volvatur, et audierit similiter opposito modo moveri, credet ei, et nisi crederet, non caperet hoc possibile. Et ita revelatione relatoris perveniet, ut sciat faciem illam omnes etiam contrariis motibus incedentes non deserere ${ }^{70}$.

El espejo revelador, en el cual la percepción (que constata una imposibilidad) se convierte en un acto de fe (que admite/cree eso que los sentidos y la razón deben, al contrario, excluir de su campo de investigación), transformando así una imposibilidad lógica en una

69 N. de Cusa, De non aliud, 23; h XIII, p. 55, lin. 33.

70 Id., De vis. Praefatio: h VI, n. 3, lin. I7-25.

Facultad de Ciencias Religiosas y Filosóficas - Universidad Católica del Maule 
necesidad, hace que se vuelva a buscar paradojalmente la verdad justamente «ahí donde se encuentra la imposibilidad (ubi impossibilitas occurrit) $\gg^{71}$. Sin esta concesión sobre la coexistencia de los opuestos, la situación vivida por los monjes degeneraría fácilmente en discordia y conflicto: la perspectiva de cada uno de los compañeros peregrinantes, al momento desu encuentroalolargo del perímetro dela semicircunferencia ideal que tiene por centro la icona Dei, en su identidad exclusiva no sería diversa de aquella, muy limitada, por el ingenuo Monopo del cual narra Alberti. Su defecto sería aquel de intercambiar la apariencia plana de la superficie con la profundidad de la verdad, absolutizando solo un lado de ella. Como ocurre, por lo demás, cuando se intercambia el color de las lentes de los propios anteojos con un atributo cromático de la realidad misma:

Sicut enim oculus iste carneus per vitrum rubeum intuens omnia, quae videt, rubea iudicat et, si per vitrum viride, omnia viridia, sic quisque oculus mentis obvolutus contractione et passione iudicat te, qui es mentis obiectum, secundum naturam contractionis et passionis ${ }^{72}$.

Respecto a esta alteración de la vista/mente, el Cusano parece abrir su propia scientia ignorationis a una crítica trascendental de los poderes del conocimiento ante litteram ${ }^{73}$, para sopesar atentamente sus posibilidades y límites; su objetivo es llevar a tomar consciencia de estos engaños de perspectiva que pueden surgir cada vez que la facultad visiva intercambia erróneamente la afección accidental debida al medio perceptivo con la verdad misma: «es necesario, por lo tanto, que aquel que especula haga como aquel que mira la nieve a través de un vidrio rojo: él ve la nieve y le atribuye al vidrio, no a la nieve, la apariencia roja» ${ }^{74}$. Dicho sea de paso, el control racional de esta posibilidad de alteración perceptiva está en el

7I Ibíd., 9; h VI, n. 36, lin. 3.

72 Ibíd., 6; h VI, n. I9, lin. II-I5.

73 La doctrina de la coincidencia en particular, según K. Flasch, señalaría el punto exacto del tránsito de la lógica racional (de matriz aristotélica), a la metafísica del Uno, a la cual accede solamente la facultad intelectiva: en ella, si se mira bien, tomaría forma aquel «conflicto entre una metafísica que se define, en modo trascendental, como investigación sobre las condiciones de posibilidad del intelecto, contra una lógica que pretende ser instrumento apropiado para toda forma de saber, incluo de aquel concerniente a Dios y al intelecto»; (K. Flasch, Die Metaphysik des Einen bei Nikolaus von Kues. Problemgeschichtliche Stellung und systematische Bedeutung, Leiden, Brill, 1973, p. 193). El evidenciar este aspecto trascendental de la doctrina de la coincidencia, continúa Flasch, no significa, sin embargo, sostener que para el Cusano «se trate de un ejercicio que tiene que ver con "puras determinaciones de pensamiento". En esta superación de las oposiciones intelectuales se manifiesta, de hecho, el carácter propio de la unidad absoluto y de esa imagen suya que es el espíritu humano» (ibíd., I95).

74 N. de Cusa, De non aliud 9; h XIII, p. 19, lin. 33-34. 
origen de la perspectiva aérea de Leonardo ${ }^{75}$.

Ese recurso a los espejos, capaces de generar la ilusión de lo integral (tutto tondo), parece sin duda en sintonía con las exigencias, respectivamente especulativas y artísticas, del Cusano y de Leonardo (este último, por lo demás, como se evidencia en el Codice Atlantico, tenía en mente un «libro de los espejos» ${ }^{76}$ : ahí donde el primero aspiraba a una visio circularis, bien ejemplificada por la mirada oblicua del ícono del omnividente que acompañaba el Libellus de icona (sive visu Dei) a la comunidad de Tegernsee ${ }^{77}$, el otro tendía a obtener una rendición escultórica en el ámbito de la pintura misma, en un arduo «tentativo de igualar la escultura con los medios del pintor» ${ }^{78}$. Obtener el relieve haciendo uso de la perspectiva lineal (o «de las pérdidas»), de aquella atmosférica y de aquella determinada por las variaciones del color, implica según Leonardo una mayor habilidad de quien actúa sobre la materia tridimensional. De aquí que, en el así llamado Paragón de las artes, la «deidad de la pintura», superior a cualquier otra forma de arte, tenga que ver con la materia bruta y el devenir temporal (música y poesía, en tanto artes diacrónicas). Miguel Ángel, que estaba obligado a trabajar sucio, sudado y manchado de polvo de piedra (estado que lo llevará al fin de sus años a sufrir del «mal de la piedra» o calculosis ${ }^{79}$ ), por un lado, y el Botticella (Sandro Botticelli), que en lugar de hacer paisajes realizado en sentido perspectivo «hizo tristísimos países» ${ }^{80}$ lanzando manchas de color sin profundidad, por el otro, ambos artistas, a los ojos de Leonardo, son deplorables personificaciones de los defectos a evitar en el arte verdadero de la pintura, que es una verdadera "metafísica de la apariencia": las imágenes vivas son aquí restituidas corposamente con un sabio artificio que respeta, con aparente fidelidad naturalista, sus volúmenes y relieves, llevando las profundidades insondables del mundo

75 Sobre estos temas remito a mi ensayo Leonardo e la reinvenzione della natura. Per un'ontologia dello sfumato, en Aa.Vv., Pensiero Tecnica Creatività. Leonardo e il Rinascimento, a cura di G. Cuozzo, A. Dall'Igna, S. Ferrari, H. Schwaetzer, Milano-Udine, Mimesis, 2020 (de próxima publicación).

76 Leonardo, Cod. Atl., fol. 25orb (nuevo 677r). Algunos pasajes sobre los espejos cóncavos se encuentran también en Cod. Ar. I, fol. 86r-86v.

77 N. de Cusa, De vis. Praefatio: h VI, n. 3, lin. 6-I3: «Primum igitur admirabimini, quomodo hoc fieri possit, quod omnes et singulos simul respiciat. Nam imaginatio stantis in oriente nequaquam capit visum eiconae ad aliam plagam versum, scilicet occasum vel meridiem. Deinde frater, qui fuit in oriente, se locet in occasu, et experietur visum in eo figi in occasu quemadmodum prius in oriente. Et quoniam scit eiconam fixam et immutatam, admirabitur mutationem immutabilis visus».

78 P. C. Marani, Lo sguardo e la musica. Il musico nell'opera di Leonardo a Milano, en Leonardo da Vinci. Il musico, a cura di P.C. Marani, Milano, Silvana Editoriale, 20I0, p. I8a.

79 Miguel Ángel, Carta al sobrino Leonardo del 5 de abril 1549, en Le lettere di Michelangelo Buonarroti, a cura di G. Milanesi, Firenze, Le Monnier, I875, p. 245.

8 o Leonardo, Trattato della pittura, cit., cap. 57, p. 58. 
a la tabla plana pictórica. En particular, Leonardo "quería obtener el relieve a través del empleo científico de la luz y de las sombras"81.

\section{3) La estrella perspectiva de Leonardo da Vinci}

En Leonardo, el tema de la visión pluri-perspectiva y tridimensional asume -mediante la así llamada "estrella perspectiva" - un rol decisivo en el contexto de la anatomía: la rotación de la mirada en $360^{\circ}$ permite, de hecho, trazar, en el dibujo, los órganos con un cierto relieve, el cual resulta funcional a una penetración fisiológica del órgano objeto de estudio/ representación. El ejemplo adoptado por Leonardo en el folio I906Ia del Codex Windsor (I5IO ca.) es aquel del polígono (octágono) inscrito en una circunferencia: cada lado de este es la base de una pirámide óptica cuya altura restituye -como dirá Alberti- el rayo céntrico de una determinada visión o pirámide visual (ocho en total). El artista, girando en torno al objeto, hace asumir a la reproducción artística de este último, desde el punto de vista gráfico, un rasgo casi escultórico, omniabarcante [a tutto tondo]: el relieve, en la pintura (como verdadera filosofía), es por lo demás la metáfora que mejor alude a la intuición intelectual (como facultad de la visión simultánea e incontracta), ápice del conocimiento científico. Intuir un objeto quiere decir verlo por adelante y atrás, tanto desde oriente como de occidente, de arriba y de abajo, restituyendo con eso, a nivel mental, una tridimensionalidad que en la experiencia cotidiana es conquistada solo con esfuerzo, luchando contra el tiempo y moviéndose en el espacio. Este, repitiendo la cita del Cusano, «ve, por lo tanto, las cosas al mismo tiempo, alrededor, arriba y abajo (in circuito et sursum e deorsum simul videt)».

Para alcanzar este resultado "escultórico", Leonardo, en la pintura, recurrió a las aplicaciones perspectivas del así llamado Mazzocchio, de su invención, representado en el Codice Atlantico ${ }^{82}$ : se trata de una rueda original construida por doscientos cincuenta y seis caras, que «servía quizás para determinar los ángulos de fuga de paredes, pisos y techos; cuanto más grande era el número de caras de este extraño poliedro, más precisa resultaba la perspectiva ${ }^{{ }^{8}}$. Cada ventana puesta sobre la extraña rueda representa un atisbo potencial desde el cual se puede representar la figura puesta idealmente al centro del instrumento,

8I K. Clark, Leonardo da Vinci: an Account of his Development as an Artist, Harmondsworth, Penguin Books, 1967, p. 158.

82 Leonardo, Cod. Atl., fol. 263vb (nuevo 7Ior).

83 M. Meneguzzo, Il movimento, in Leonardo da Vinci, Disegni. Linvenzione e l'arte nel linguaggio delle immagini, Note introduttive di A. Marinoni, Testi di M. Meneguzzo, Verona, Edizioni Futuro, 198I, pp. I66a-167b. 
siguiendo, con la técnica del difuminado, una intuición omniabarcante [a tutto tondo], teniendo bien en cuenta, sin embargo, que, como escribe el Cusano, «cuantos más angulos tendrá el polígono inscrito, será tanto más semejante al círculo: sin embargo, no será jamás igual a él, incluso si multiplicáramos sus ángulos al infinito, a menos que no se resuelva en identidad con el círculo» ${ }^{84}$.

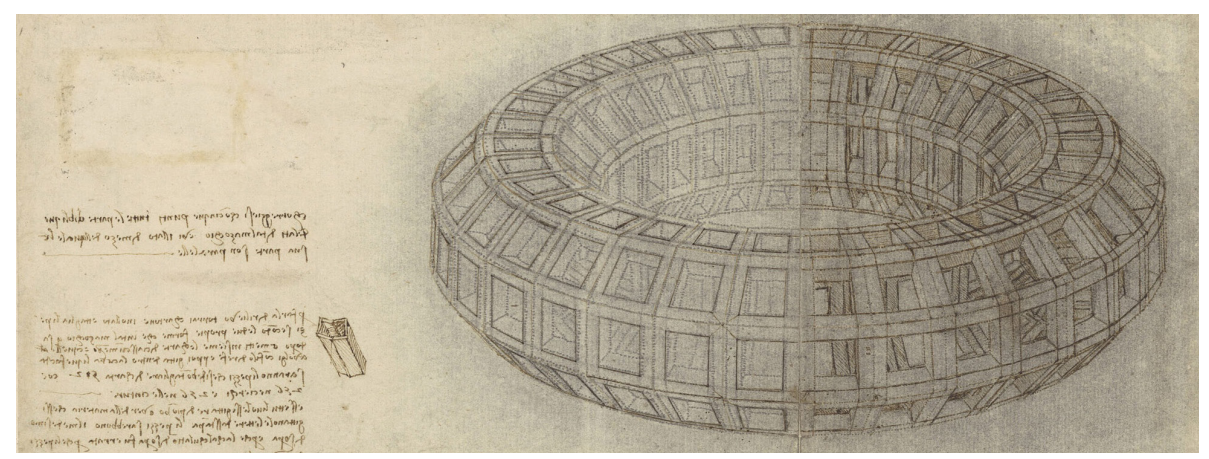

Leonardo da Vinci, Mazzocchio, en el Codice Atlantico, fol. 263 vb (nuevo 7Ior)

En la página mencionada del códice Windsor, la sección anatómica de brazo y hombro está entonces recogida a través de múltiples vistas simultáneas, contínuas variaciones del punto de observación capaces de generar una «secuencia cinematográfica de ocho angulaciones» ${ }^{85}$ : «si tú quieres conocer bien las partes del hombre anatomizado, tú lo giras o a él o a tu ojo por diversos aspectos, aquello considerando por abajo y por arriba y por los lados, girándolo y buscando el origen de cada miembro» ${ }^{86}$.

Por lo tanto, que por mi dibujo te sea evidente cada parte y cada todo mediante la demostración de 3 diversos aspectos de cada una de las partes, para que cuando habrás visto algún miembro de la parte de adelante con algún

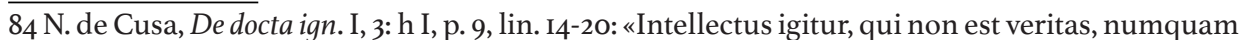
veritatem adeo praecise comprehendit, quin per infinitum praecisius comprehendi possit, habens se ad veritatem sicut polygonia ad circulum, quanto inscripta plurium angulorum fuerit, tanto similior circulo, numquam tamen efficitur aequalis, etiam si angulos in infinitum multiplicaverit, nisi in identitatem cum circulo se resolvat».

85 M. Kemp, Leonardo da Vinci. Le mirabili operazioni della natura e dell'uomo (198I), trad. it. di F. Saba Sardi, Milano, Mondadori, 1982, p. 270; cfr. Id., Lezioni dell'occhio. Leonardo da Vinci discepolo dell'esperienza, trad. it. di M. Parizzi, Milano, Vita \& Pensiero, 2004, p. 8I.

86 Leonardo, Windsor, fol. I906Ia; cfr. The literary Works of Leonardo da Vinci, compiled and edited from the original manuscripts by J.P. Richter, 2 voll, Londra, Searle \& Rivington, I882, vol. II, p. 87, fr. 798. 
nervio, cordón o vena que nazca de la parte opuesta, te sea demostrado el mismo miembro girado de lado o derecho; no de otra manera como si tuiveras en la mano el mismo miembro y lo estuvieras girando parte por parte hasta llegar a tanto que tuvieras pleno conocimiento de lo que deseas saber, y así similarmente se te pongan en frente tres o 4 demostraciones de cada miembro por diversos aspectos, de modo que quedarás con un verdadero y pleno conocimiento de aquello que quieres saber de la figura del hombre ${ }^{87}$.

Al fondo a la derecho de la página mencionada del Códice Windsor, Leonardo retrata estas ocho pirámides visivas con la consueta figura de estrella $-\mathrm{O}$ «corona de pirámides trazadas alrededor de una esfera ${ }^{88}$, de evidente ascendencia albertiana ${ }^{89}$, , que podría ser empleada tal cual es para representar esquemáticamente el contenido del escrito cusano sobre la filiación de Dios, obra en la cual está operativo el corazón de la teoría hermenéutica del Cusano centrada en la unidad de lo verdadero y en la multiplicidad diversa de los modos de asimilación de la identidad simple del principium ${ }^{90}$. A este fin, bastaría con imaginar que cada vértice piramidal sea un espejo mental particular, que expresa un irreductible modus theophanicus, espejo dispuesto a lo largo del perímetro que tiene como centro la verdad, el speculum infinito de Dios, absolutamente perfecto y sin ninguna contracción:

Dico igitur: claritas una specularis varie in istis universis resplendet specularibus reflexionibus et in prima rectissima speculari claritate omnia specula uti sunt resplendent, uti in materialibus speculis in circulo anteriori ad se versis videri potest. In omnibus autem contractis et curvis omnia non uti ipsa sunt apparent, sed secundum recipientis speculi condicionem, scilicet cum diminutione ob recessum recipientis speculi a rectitudine ${ }^{9 \mathrm{I}}$.

87 Windsor, fol. 1906Ia; cfr. The literary Works of Leonardo da Vinci, cit., vol. II, p. 88, fr. 798. 88 M. Kemp, Leonardo da Vinci. Le mirabili operazioni della natura e dell'uomo, cit., p. II5.

89 Cfr. Alberti, De pictura (I435), trad. it. de L. Dominichi, Venezia, Gabriel Giolito de Ferrari, I547 (reimpresión anastática: Bologna, Forni, I988), Libro I 2, p. I2, en el cual el autor describe la así llamada «guirnalda del círculo».

90 N. de Cusa, Sermo CCLVIII (Multifarie multisque modis, Bressanone I456): h XIX, n. I7, lin. 4-I9: «Omnis elocutio est interni conceptus vel verbi explicatio. Et quia numquam potest verbi essentia explicari, ideo "multifarie multisque modis" loquitur Deus per creaturam, ut in varietate tali melius verbi simplicitas et simplicitatis fecunditas explicetur sicut vis simplicis radii solaris est inexpressibilis fecunditatis et ad hoc ostendendum "multifarie multisque modis" suam virtutem ostendit in generabilibus istius sensibilis mundi, etiam supra oppositionem, quando indurat lutum et resolvit nivem seu ceram. Sicut igitur experimur in varietate virtutum terrae nascentium inexpressibilem solis virtutem in radio suo, sic in prophetis experimur inexpressibilem Dei virtutem in verbo suo».

9I Id., De fil. 3: h IV, n. 66, lin. I-7. 


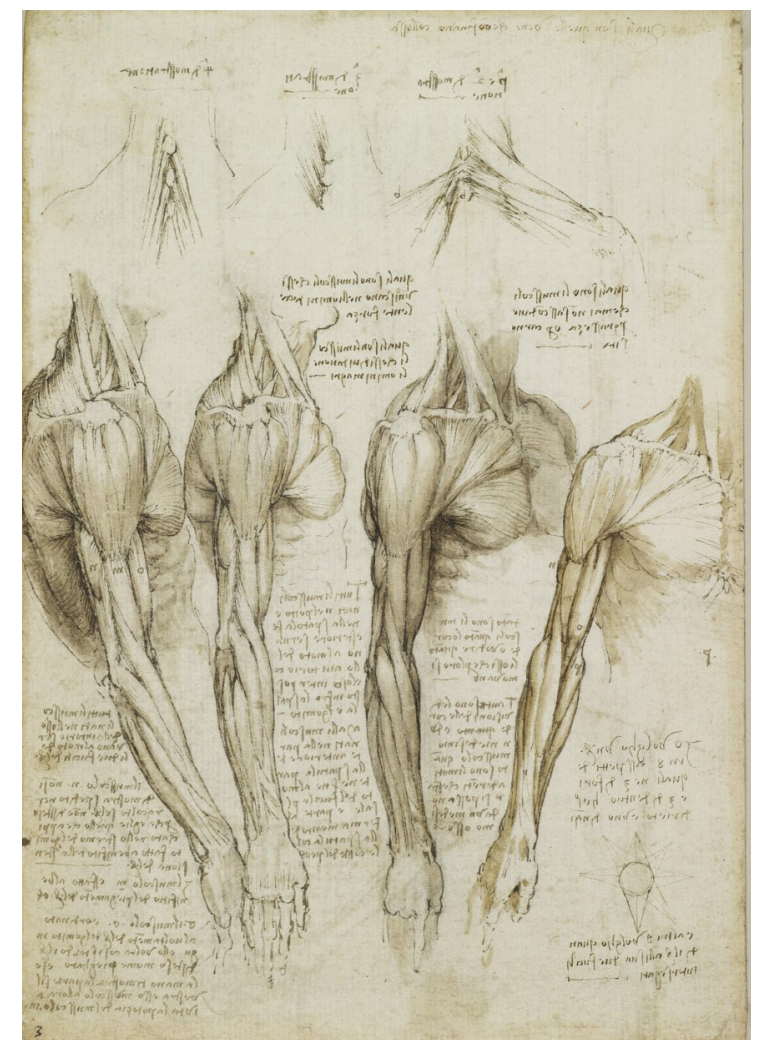

Leonardo da Vinci, Codice Windsor, fol. I906ra, Royal Collection, Windsor Castel (Berkshire)

Otra admirable aplicación de la estrella perspectiva (y del Mazzocchio) está testimoniada por el dibujo en piedra roja sobre carta Tres vistas de cabeza viril con barba (ca. I502), conservado en la Biblioteca Real de Turín. En él un mismo personaje (¿César Borgia?) está retratado, de izquierda a derecha, de perfil, en tres cuartos y frontalmente. Se trata de una escansión cinematográfica que presupone una rotación de $90^{\circ}$ por parte del observador alrededor de la figura, a partir del lado izquierdo, «según la sucesión "zurda" de Leonardo»92. No se excluye que el dibujo hubiera tenido como finalidad la realización de una escultura, «para la cual las tres vistas constituyen las referencias de base para el desarrollo global [a tutto tondo]»93. En cualquier caso, como decíamos, es el mismo

92 P. Salvi, Schede. Volti tra realtà e idealizzazione, in Aa.Vv., Leonardo da Vinci. Disegnare il futuro, a cura di E. Pagella, F.P. Di Teodoro e P. Salvi, Catalogo della Mostra presso i Musei Reali - Galleria Sabauda (Torino, I6 aprile - I4 luglio 20I9), Milano, Silvana Editoriale, 20I9, p. 380.

93 Ibíd. 
dibujo que, para Leonardo, debe sustituir, en todo y por todos lados, la reproducción tridimensional de la escultura, al modo de una viva imago.

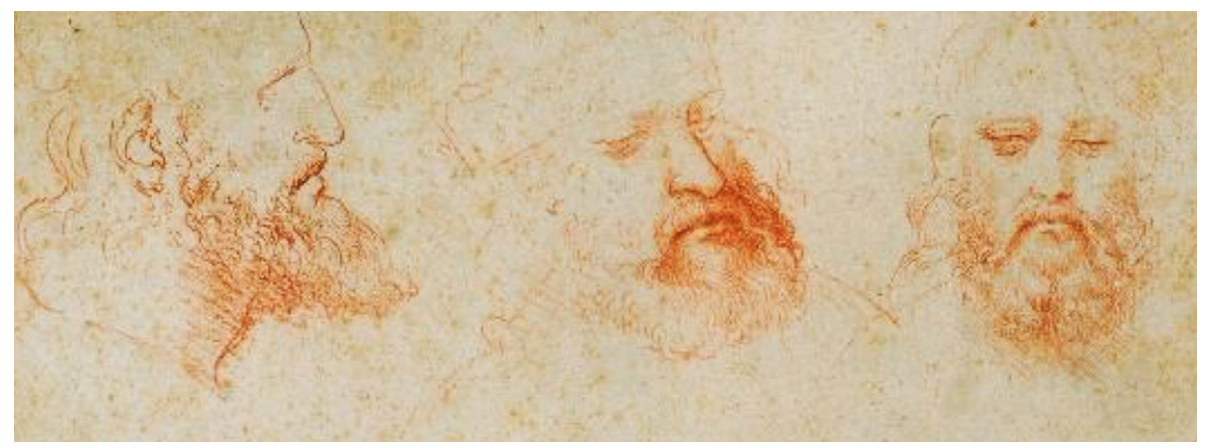

Leonardo da Vinci, Tres vistas de cabeza viril con barba (ca. I502), Museos Reales (Turín)

La doctrina del Paragón de Leonardo, parte conspícua de los textos elaborados por Francesco Melzi para la composición del Tratado de la pintura ${ }^{94}$, es una reivindicación de la superioridad del dibujo y de la pintura, las cuales se sustraen -al contrario del discurso- a la sucesión temporal, y en esta sincronía de la aprehensión en figura consiste «la superioridad de la imagen sobre la palabra»95: «un mismo tiempo, en el cual se encierra la especulación de una belleza pintada, no puede dar una belleza descrita, y se comete un pecado contra la naturaleza cuando aquello que se debe introducir por el ojo se lo quiere introducir por la oreja» ${ }^{96}$. De hecho, escribe Leonardo, la proporcionalidad

94 Para la historia del manuscrito y de las ediciones impresas del Trattato, es necesario recordar que "Francesco Melzi compiló, hacia el 1550, antes de las dispersión y mutilación de los manuscritos del maestro, un manuscrito titulado Libro de pintura, sirviéndose de dieciocho autógrafos leonardescos": M.V. Guffanti, La fortuna di Leonardo nelle edizioni a stampa del Trattato della pittura e nei suoi estratti, en Leonardo. Dagli studi di prospettiva al Trattato della pittura, a cura di P.C. Marani e M.T. Fiorio, Electa, Milano, 2007, p. I2Ib. El manuscrito de Melzi es conocido hoy como Cod. Vaticano Urbinate lat. 1270. Otra fuente para la circulación de las doctrinas sobre el arte de Leonardo es la publicación, en 1584, del ya mencionado Trattato dell'arte della pittura, scultura e architettura (1584) de Giovanni Paolo Lomazzo, perteneciente a la veta de la tradición leonardesca central, amigo de Melzi y en posesión de algunos manuscritos leonardescos: su obra acoge casi ciertamente una parte del famoso Paragón de Leonardo, "que no terminó en el Códice Vaticano Urbinate lat. I270 quizás porque es ajenea a la herencia melziana y por ende inaccesible": M. V. Guffanti, Ficha I7, en Leonardo. Dagli studi di proporzioni al Trattato della pittura, cit., p. 8Ic. La primera edición impresa del Trattato della pittura di Leonardo da Vinci es más bien tardía, y se debe a Raffaele Du Fresne, que la publica en París en I65I sobre la base del material reunido por Cassiano dal Pozzo con la adición del De statua (con el título Trattato della statua) de L. B. Alberti. 95 M. Kemp, Leonardo da Vinci. Le mirabili operazione della natura e dell'uomo, cit., p. 67.

96 Leonardo, Trattato della pittura, cit., cap. 19, p. 32. 
divina - principio de toda belleza y armonía- consiste en la relación entre los miembros singulares «juntas compuestas» en relación con el todo, así como también de cada parte con la totalidad, en la cual «solo en un tiempo componen aquella divina armonía de ese conjunto de miembros» ${ }^{97}$. Se trata, como bien se ve, de la transposición en imágenes de la noción musical de concierto [concento], el acuerdo entre las diversas voces «agregadas juntas a un mismo tiempo» ${ }^{98}$. En efecto, en el plano de la voz (y, por lo tanto, de la poesía), el concierto es inalcanzable: la música, en tanto discurso sonoro, ofrece solo una imagen opaca de la verdadera concinnitas, porque aquí cada voz se escucha «por sí sola en diversos tiempos», no pudiendo el auditor alcanzar jamás la perfecta composición simultánea de las partes singulares en una forma completa, estable, cerrada en sí y sin tiempo. Sería como «si quisiéramos mostrar un rostro por partes, siempre cubriendo aquello que mostraron antes, de cuya demostración el olvido no deja componer ninguna proporcionalidad de armoniía, porque el ojo no las abraza con su virtud visiva a un mismo tiempo"; ahora bien, "algo semejante acaece en las bellezas de cualquier cosa figurada por el poeta, de las cuales, porque sus partes son dichas separadamente en tiempos separados, la memoria no capta ninguna armonía»99. "Brevedad" e "largueza de tiempo" en su antítesis corresponden, respectivamente, a pintura y poesía: solo la obra de la primera «es comprendida inmediatamente por sus espectadores» ${ }^{\text {10o}}$. Ya que, continúa Leonardo, «la pintura te representa en un instante su esencia en la virtud visiva y, por el propio medio de donde la impresiva recibe los objetos naturales, e incluso al mismo tiempo en el cual se compone la armónica proporcionalidad de las partes que componen el todo»; por el contrario, la poesía «no se da cuenta de que sus palabras, al hacer mención de los miembros de tal belleza, el tiempo las divide la una de la otra, entromete al olvido y divide las proporciones, las cuales sin gran prolijidad no puede nombrar ${ }^{\perp \text {.o. }}$.

Esta complicidad teórica entre Nicolás de Cusa y Leonardo da Vinci relativa a la visio circularis (que de metáfora teológica regresa a su dimensión artística) no deja de sorprender. Por una justificación histórico-filológica de la posible familiaridad de parte de Leonardo con la obra del Cusano me remito a mis otros escritos ${ }^{102}$ : ella, en síntesis,

97 Ibíd., cap. 28, p. 40.

98 Ibíd., cap. I7, p. 30.

99 Ibíd., cap. I7, pp. 30-I.

Ioo Ibíd., cap. I8, p. 3I.

IoI Ibíd., cap. 19, pp. 3I-2.

I02 En particular a mi libro Dentro l'immagine. Natura, arte e prospettiva in Leonardo da Vinci,

Facultad de Ciencias Religiosas y Filosóficas - Universidad Católica del Maule 
tiene que ver con la historia de la edición de Benedetto Dolcibelli di Cortemaggiore, del $\mathrm{I}_{52} \mathrm{O}^{103}$, y con las relaciones entre el mismo Leonardo y el gobernador de la Lombardía Charles D’Amboise, «amigo y protector» del artista en la época de su segunda estadía milanesa (I506-1513) ${ }^{104}$, además de ser sobrino del cardenal Georges D'Amboise ${ }^{\mathrm{ios}}$, a quien las Opera omnia estaban dedicadas por Rolando Pallavicini (coeditor junto con Dolcibelli). Pero se trata solo de un primer paso en un recorrido de constataciones entrecruzadas que podrían ver envueltas a otras figuras destacadas del período. El ya mencionado Luca Pacioli es uno de los candidatos con mayor autoridad ${ }^{106}$.

Bologna, il Mulino, 20I3.

I03 In Marchionis Pallavicini castello quod Castrum Laurum vocatur (Cortemaggiore), per Benedictum Dolcibellum, I502. Cfr. G. Santinello, Edizione delle opere; in Id., Introduzione e Niccolò Cusano, Roma-Bari, Laterza, 1987, pp. I82-I83.

IO4 C. Pedretti, "Scrivi che cosa è anima", en Leonardo \& io, Milano, Mondadori, 2008, p. 48. I05 Cfr. Id., I fratelli Gaurico, en Leonardo E io, cit., p. 318.

I06 Sobre la figura de Pacioli en sus relaciones con Leonardo, Dürer y Bramante, remito al estudio fundamental de S. Ferrari, Luca Pacioli a Milano fra Leonardo, Bramante e Dürer, en Luca Pacioli tra Piero della Francesca e Leonardo, cit., pp. 37-50. 
